\title{
JEAN-PIERRE PLISSON, André Breton. Le fil rouge des enchantements
}

\section{Tania Collani}

\section{(2) OpenEdition}

\section{Journals}

\section{Edizione digitale}

URL: https://journals.openedition.org/studifrancesi/44198

DOI: 10.4000/studifrancesi.44198

ISSN: 2421-5856

\section{Editore}

Rosenberg \& Sellier

\section{Edizione cartacea}

Data di pubblicazione: 1 juin 2021

Paginazione: 242

ISSN: 0039-2944

\section{Notizia bibliografica digitale}

Tania Collani, «JEAN-PIERRE PLISSON, André Breton. Le fil rouge des enchantements», Studi Francesi [Online], 193 (LXV | I) | 2021, online dal 01 juillet 2021, consultato il 15 octobre 2022. URL: http://

journals.openedition.org/studifrancesi/44198; DOI: https://doi.org/10.4000/studifrancesi.44198

Questo documento è stato generato automaticamente il 15 octobre 2022.

\section{(2) $\Theta \Theta \Theta$}

Creative Commons - Attribuzione - Non commerciale - Non opere derivate 4.0 Internazionale - CC BYNC-ND 4.0

https://creativecommons.org/licenses/by-nc-nd/4.0/ 


\title{
JEAN-PIERRE PLISSON, André Breton. Le fil rouge des enchantements
}

\author{
Tania Collani
}

\section{NOTIZIA}

JEAN-PIERRE PLISSON, André Breton. Le fil rouge des enchantements, Montreuil, Les éditions du travail, 2018, $537 \mathrm{pp}$.

1 L'autore del presente volume, Jean-Pierre Plisson, non è un accademico e il suo incontro con il surrealismo avviene, secondo la nota bibliografica in quarta di copertina, nel 1964, su basi di consonanza estetica (la fotografia soprattutto) e ideologica (la militanza politica nella macro-sfera comunista e socialista). Les éditions $d u$ travail, presso le quali è pubblicata questa monografia, sono una giovane casa editrice di Montreuil, il cui obiettivo primario non è la pubblicazione di elaborati scientifici, ma la diffusione di opere basate sulle battaglie sociali, sulla storia e l'attualità (secondo quanto riportato nel sito della casa editrice).

2 Jean-Pierre Plisson esprime a più riprese la sua volontà di ancorare la vicenda del surrealismo alla storia politica e sociale di più di cinquant'anni del Novecento, ridimensionando la primarietà della riflessione poetica e prendendo come cardine delle sue incursioni la figura di André Breton. Nel corso della sua opera, incontriamo dunque una serie di episodi-chiave che rivitalizzano il parallelo tra la "Rivoluzione comunista" e la "Rivoluzione surrealista": l'esito della Prima Guerra mondiale; lo slancio utopico della Rivoluzione d'Ottobre e la vicenda di Lenin; il partito comunista francese e i periodici che stringono un accordo di collaborazione con i surrealisti; i poeti e gli uomini politici riuniti, seppur provvisoriamente, dalla stessa causa rivoluzionaria Aragon, Péret, Majakovskij, Trotskij, Nezval.

3 Anche se a livello metodologico il lettore può trovarsi talvolta spiazzato da una costruzione argomentativa che soccombe all'imperativo cronologico e da alcune semplificazioni su movimenti come il romanticismo, il libro mobilita una grande 
documentazione ed è piacevole poter ripercorrere la giovinezza di Breton militante socialista e antimilitarista, i suoi incontri e scambi con Jacques Vaché e Théodore Frankel, la sua scoperta di Mallarmé, Rimbaud e Lautréamont, che porterà al parallelo fondante dell'estetica/etica del surrealismo di una poesia collettiva, che rivendica al tempo stesso una filiazione marxista e poetico-simbolista, solo in apparenza paradossale.

4 Nella sezione dedicata alla fine del "Papa del surrealismo" («Avoir maintenu les "postulats initiaux"», pp. 455-459), Breton viene dipinto come un uomo e un poeta retto e coerente con i suoi ideali di partenza: il grande potenziale della gioventù, l'anticapitalismo, l'opposizione a un'attitudine conservatrice della borghesia, la vibrazione meravigliosa della vita, la fedeltà ai principi del comunismo utopico contro la vicenda stalinista. E non è un caso che il volume di Plisson si prolunghi al di là della morte di Breton (avvenuta nel settembre 1966), per arrivare a inglobare anche $i$ movimenti francesi di maggio 1968 e due incursioni internazionali nelle vicende di Cuba e di Praga. Si tratta di un tentativo di risposta alla domanda che tutti i critici del movimento surrealista ciclicamente si pongono: il movimento surrealista sopravvive ad André Breton?

Nella sezione «Dissolution du “mouvement surréaliste"» (pp. 475-476), Plisson ripercorre il dibattito del 1969 arrivato fin nelle colonne del quotidiano «Le Monde», tra Schuster e Alquié, per finire in toni forse un po' troppo categorici sulla presupposta condanna che la critica avrebbe emesso nei confronti di Breton e del suo movimento. Ci sembra vero il contrario, piuttosto: ovvero che certi presupposti e aforismi surrealisti sono periodicamente d'attualità sulla scena poetica, teatrale e artistica. Forse anche la veemenza di Plisson nei confronti della ricezione americana del movimento dovrebbe essere smorzata nelle sue punte più acutamente militanti a livello ideologico: con tutte le sfumature di ogni singolo caso, il fatto che un movimento come il surrealismo dia vita a un grande numero di tesi, seppur concentrate più sull'aspetto poetico che su quello politico, dimostra invece che la grande analogia di Breton persiste a distanza di tempo, a discapito di tutti i critici che, di volta in volta, vogliono imporre una visione granitica su una vicenda così complessa e duratura come quella del movimento surrealista. 